This item was submitted to Loughborough's Research Repository by the author.

Items in Figshare are protected by copyright, with all rights reserved, unless otherwise indicated.

\title{
Effect of racket-shuttlecock impact location on shot outcome for badminton smashes by elite players
}

\section{PLEASE CITE THE PUBLISHED VERSION}

https://doi.org/10.1080/02640414.2020.1792132

\section{PUBLISHER}

Informa UK Limited, trading as Taylor \& Francis Group

VERSION

AM (Accepted Manuscript)

\section{PUBLISHER STATEMENT}

This is an Accepted Manuscript of an article published by Taylor \& Francis in Journal of Sports Sciences on 14 July 2020, available online: http://www.tandfonline.com/10.1080/02640414.2020.1792132.

\section{LICENCE}

CC BY-NC-ND 4.0

\section{REPOSITORY RECORD}

McErlain-Naylor, Stuart, Harley Towler, Idrees Afzal, Paul Felton, Michael Hiley, and Mark King. 2020. "Effect of Racket-shuttlecock Impact Location on Shot Outcome for Badminton Smashes by Elite Players". Loughborough University. https://hdl.handle.net/2134/12923480.v1. 


\title{
Effect of racket-shuttlecock impact location on shot outcome for badminton smashes by elite players
}

\author{
${ }^{1,2}$ S.A. McErlain-Naylor, ${ }^{1}$ H. Towler, ${ }^{1}$ I.A. Afzal, ${ }^{1,3}$ P.J. Felton, ${ }^{1}$ M.J. Hiley, and \\ ${ }^{1}$ M.A. King.
}

${ }^{1}$ School of Sport, Exercise and Health Sciences, Loughborough University, Loughborough, LE11 3TU, UK

${ }^{2}$ School of Health and Sports Sciences, University of Suffolk, Ipswich, IP4 1QJ, UK

${ }^{1}$ School of Science and Technology, Nottingham Trent University, Nottingham, NG11 8NS, UK

\begin{abstract}
A logarithmic curve fitting methodology for the calculation of badminton racket-shuttlecock impact locations from three-dimensional motion capture data was presented and validated. Median absolute differences between calculated and measured impact locations were 3.6 [IQR: 4.4] and 3.5 [IQR: 3.5] mm medio-laterally and longitudinally on the racket face, respectively. Three-dimensional kinematic data of racket and shuttlecock were recorded for 2386 smashes performed by 65 international badminton players, with racket-shuttlecock impact location assessed against instantaneous post-impact shuttlecock speed and direction. Medio-lateral and longitudinal impact locations explained 26.2\% (quadratic regression; 95\% credible interval: $23.1 \%, 29.2 \% ; \mathrm{BF}_{10}=1.3 \times 10^{131}$, extreme; $p<0.001$ ) of the variation in participant-specific shuttlecock speed. A meaningful $\left(\mathrm{BF}_{10}=\infty\right.$, extreme; $p<0.001$ ) linear relationship was observed between medio-lateral impact location and shuttlecock horizontal direction relative to a line normal to the racket face at impact. Impact locations within one standard deviation of the pooled mean impact location predict reductions in post-impact shuttlecock speeds of up to $5.3 \%$ of the player's maximal speed and deviations in horizontal direction of up to $2.9^{\circ}$ relative to a line normal to the racket face. These results highlight the margin for error available to elite badminton players during the smash.
\end{abstract}

Keywords: racket; shuttle; contact; speed; direction

\section{INTRODUCTION}

The forehand overhead smash accounts for $54 \%$ of 'unconditional winner' and 'forced failure' shots in international badminton competition (Tong \& Hong, 2000). Smash success is a function of post-impact shuttlecock speed and the ability to direct the shuttlecock to a desired location (Kwan, Andersen, Cheng, Tang, \& Rasmussen, 2011; Zhang et al., 2016). Post-impact shuttlecock speeds have been reported as high as 100 and $118 \mathrm{~m} \cdot \mathrm{s}^{-1}$ in research literature (King, Towler, Dillon, \& McErlain-Naylor, 2020) and elite competition (Guinness World Records, 2017), respectively. Research across a range of other projectile hitting sports has highlighted the importance of impact location on these outcomes, with off-centre impacts resulting in slower speeds and launch angles further from normal to the racket or bat face (Bower, 2012; Elliott, Blanksby, \& Ellis, 1980; Knudson, 1993; Peploe, McErlain-Naylor, Harland, \& King, 2018; Symes, 2006). Despite the practical implications of research in sports such as cricket (Peploe, McErlain-Naylor, Harland, \& King, 2018), no research to date has investigated the effects of impact locations across the racket face on shot outcome in elite-level badminton.

The optimal impact location in racket sports can be theoretically defined according to: the vibration node; the centre of percussion; the area of maximum coefficient of restitution; or dead spot (Kotze, Mitchell, \& Rothberg, 2000). In sport- 
specific tasks such as the badminton smash, post-impact shuttlecock speed is determined not only by the impact efficiency but also by the velocity and effective mass of the point on the racket at which impact occurs. For example, longitudinally distal positions on the racket face will have a greater linear velocity for any given angular velocity of the racket than more proximal positions but also a lower effective mass (Brody, Cross, \& Lindsey, 2002; Kwan, 2010). As such, the apparent coefficient of restitution, i.e. the ratio of rebound ball/shuttlecock speed to incident speed, or the post-impact speed alone, may be better measures of impact quality from the perspective of sporting performance. Furthermore, racket and string properties may influence shot outcome. It is possible that a racket of greater stiffness would provide a more consistent response due to reduced racket deflection (Kwan, 2010). Additionally, variations in the string material and tension will result in differences in the deformation of the stringbed and shuttlecock and thus affect the energy returned to the shuttlecock post-impact (Miller, 2006). A racket with a greater polar moment of inertia has greater resistance to twisting throughout the contact period and would thus be expected to produce less deviation in post-impact shuttlecock direction (Brody \& Roetert, 2004).

One early study by Elliott et al. (1980) projected tennis balls at fixed locations on a stationary hand-held tennis racket. They found close to optimum post-impact ball speeds at locations within $2 \mathrm{~cm}$ medio-laterally of the racket face midline and within 2 - $6 \mathrm{~cm}$ longitudinally proximal of its geometric centre. Knudson (1993) further showed, using clamped oversized tennis rackets, that medio-laterally off-centre impacts projected the ball further from a line normal to the racket face when compared to central impacts. This was likely due to a greater racket polar rotation. This effect was augmented as string tension was increased. The low racket head speeds or clamped nature of rackets call into question the validity of such results to the high-speed impacts during a dynamic maximal effort badminton smash (Banwell, 2013; Brody, 1995; Gawande, Kale, \& Pachpore, 2017; Kwan et al., 2011; Kwan \& Rasmussen, 2010; Mcintyre \& Pfautsch, 1982; Noble \& Eggeman, 1982; Shibayama \& Ebashi, 1983; Stretch, Buys, Du Toit, \& Viljoen, 1998).

In the badminton smash, Kwan (2010) modelled the transfer of momentum at racket-shuttlecock impact, reporting that inclusion of the measured longitudinal impact location increased the correlation coefficient between measured (10 ms post-impact) and predicted post-impact shuttlecock speeds from 0.227 to 0.675 compared to when central impacts were assumed, thus highlighting the importance of impact location in generating smash speed. The authors reported difficulties tracking the shuttlecock immediately after impact due to shock and reversal of direction, whilst deceleration of the shuttlecock prior to measurement resulted in predicted speeds generally exceeding measured speeds. Furthermore, the model did not allow for variation in incoming shuttlecock velocity, or varying coefficient of restitution across the stringbed $(\mathrm{H}$. Brody, 1997). The five participants, including two novices, achieved shuttlecock speeds (measured $<70 \mathrm{~m} \cdot \mathrm{s}^{-1}$; predicted $<80 \mathrm{~m} \cdot \mathrm{s}^{-1}$ ) inferior to those of elite players. No study has reported racket-shuttlecock impact characteristics in elite badminton populations.

The high instantaneous shuttlecock speeds (up to $118 \mathrm{~m} \cdot \mathrm{s}^{-1}$; Guinness World Records, 2017) and short impact durations (approximately $1 \mathrm{~ms}$; Cohen, Texier, Quéré, \& Clanet, 2015) found in badminton make it difficult to identify impact timing and location on the racket face. A methodology recently validated for this purpose in cricket batting (Peploe, McErlain-Naylor, Harland, Yeadon, \& King, 2018) fits logarithmic mechanical equations to pre- and post-impact ball trajectories, as well as cubic equations to the trajectories of the bat face corners, based on three-dimensional motion capture data. These equations enable researchers to determine impact characteristics in the local coordinate system of the bat face, identifying impact 
locations to within $6.4 \pm 4.2 \mathrm{~mm}$ medio-laterally and $7.1 \pm 4.4 \mathrm{~mm}$ longitudinally of measured locations during cricket range hitting.

The calculation of instantaneous post-impact ball speed and direction from trajectory equations (Peploe, McErlain-Naylor, Harland, \& King, 2018) is particularly relevant to badminton where the shuttlecock experiences great deceleration (Nakagawa, Hasegawa, Murakami, \& Obayashi, 2012). An analysis of the effect of impact location on shuttlecock velocity during the badminton smash of elite players could provide practical applications regarding margins for error and the relative importance of racket head speed compared to accurate and consistent impact locations, as previously applied in cricket (Peploe, McErlain-Naylor, Harland, \& King, 2018, 2019). Given differences in hitting implement mass, surface, and speed, as well as both pre- and post-impact projectile speeds, any methodology from alternative sports must first be validated in a badminton-specific task and environment.

As such, the aim of this study was: firstly, to determine the validity of a logarithmic curve fitting methodology for the calculation of racket-shuttlecock impact location in the badminton smash; and secondly, to assess the effects of racket-shuttlecock impact location on shot outcome, consisting of instantaneous post-impact shuttlecock speed and direction during badminton smashes by elite players. It is hypothesised that: firstly, impacts further from an optimal location on the racket face will result in reduced postimpact shuttlecock speeds; and secondly, impacts medio-laterally further from an optimal location will result in shuttlecock horizontal deviations further from a direction normal to the racket face at impact.

\section{METHODS}

All data (Stages 1 and 2 - see below) were recorded using an 18 camera Vicon Motion Analysis System (OMG Plc, Oxford, UK) recording at $400 \mathrm{~Hz}$. Cameras were mounted on tripods around a standard badminton court, covering a $7 \times 3 \times 3$ m volume in which the smash was to be played, and calibrated via standard wand calibration. Testing procedures were explained to each participant, and informed written consent obtained in accordance with the Loughborough University Ethical Advisory Committee. All participants completed a thorough self-selected warm-up and were permitted selfselected rest between trials.

\section{Stage 1 - Impact Location Methodology Validation Data Collection}

One male international badminton player (26 years, $1.78 \mathrm{~m}, 78.0 \mathrm{~kg}$ ) performed forty standing forehand overhead smashes with the shuttlecock hand-fed by another international player. The participant aimed for a position behind the centre on the opposite side of the court to recreate match demands. Six $15 \mathrm{~mm}$ wide pieces of retroreflective scotch tape were attached to the participant's own racket head frame at the locations illustrated in Figure 1. A further piece was attached around the base of the shuttlecock (AS50, Yonex, Japan) cork (Figure 1). The remaining cork was coated with stencil ink prior to each trial. The shuttle was hand-fed (necessary due to wet ink) to replicate a lift shot, with speed, angle to the vertical, and height at impact of $4.3 \pm$ $0.2 \mathrm{~m} \cdot \mathrm{s}^{-1}, 31.5 \pm 6.2^{\circ}$, and $2.30 \pm 0.09 \mathrm{~m}$ respectively. Following each trial, the racket face, with inked impact location impression (Figure 1), was photographed for subsequent digitisation, and the ink removed. Misshapen or broken shuttlecocks were removed. 


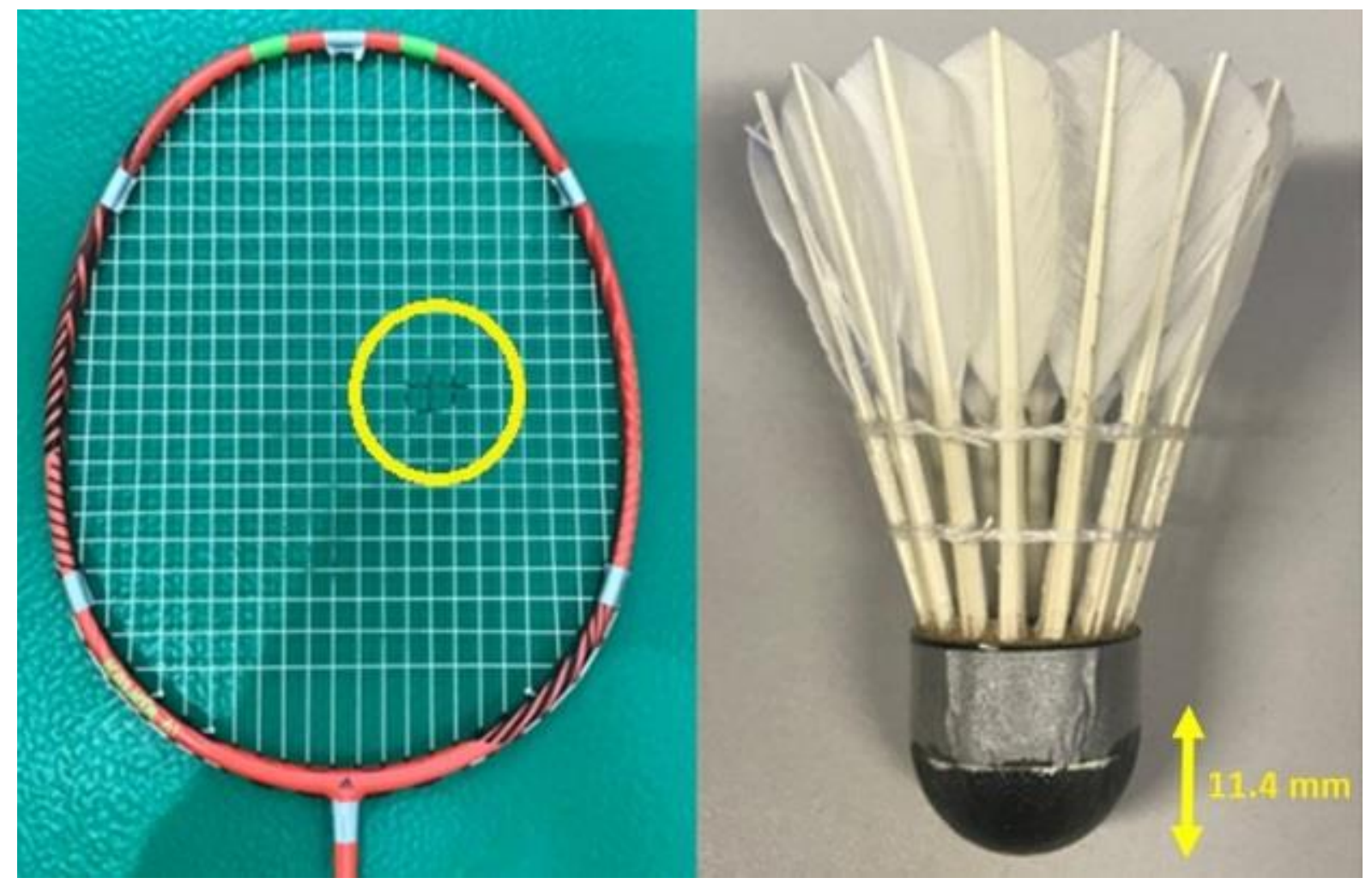

Figure 1 - Reflective tape positioned on the badminton racket and shuttlecock. Circle highlights impact location on the racket face, imparted by stencil ink applied to the shuttlecock cork. Arrow indicates shuttlecock tip to reflective tape centre distance.

\section{Data Reduction}

Marker position data were manually labelled and processed for each trial within Vicon software version 2.8.0. All further processing was performed in MATLAB (Version R2017b, The MathWorks Inc., Natick, MA). Racket-shuttlecock impact characteristics were determined using Peploe et al.'s (2018) logarithmic curve fitting methodology: Equation (1) was fit to pre- and post-impact shuttlecock displacement data separately in the global anterior-posterior and medio-lateral directions, derived from knowledge that the drag force acting on a body is proportional to the squared velocity of that body and that the deceleration of a body is proportional to the force acting on it (see Peploe et al (2018) for more detail); Equation (2) was fit to pre- and post-impact shuttlecock displacement data separately in the global vertical direction, derived via the addition of acceleration due to gravity (see Peploe et al (2018) for more detail and an assessment of the equation constants and inherent assumptions).

$$
\begin{aligned}
& x=\frac{1}{k} \cdot \ln \left(1+k \cdot v_{0} \cdot t\right) \\
& x=\frac{1}{2 k} \cdot \ln \cdot \frac{\left(g-k \cdot v_{0}^{2}\right)}{\left[g-k \cdot a^{2} \cdot \frac{\left(1-\frac{a+v_{0}}{a-v_{0}} \cdot e^{2} \cdot a \cdot k \cdot t\right)^{2}}{\left(1+\frac{a+v_{0}}{a-v_{0}} \cdot e^{2} \cdot a \cdot k \cdot t\right)^{2}}\right]}
\end{aligned}
$$

where $x$ is the displacement, $t$ is the time, $k$ and $v_{0}$ are constants determined during curve fitting, and $a=\sqrt{\frac{g}{k}}$. This curve fitting methodology was adapted for badminton in a number of ways: firstly, impact time was derived from pre- and post-impact shuttlecock displacement curve intersection in the global anterior-posterior axis, the 
main direction of shuttlecock displacement (Peploe, McErlain-Naylor, Harland, Yeadon, et al., 2018); secondly, an intermediate $1 \mathrm{~ms}$ racket-shuttlecock contact period (Cohen et al., 2015) was added between the pre- and post-impact shuttlecock curves, with the shuttlecock velocity equal to that of the racket face; finally, the local coordinate system of the racket was defined with the origin at the midpoint of markers at the tip and throat (distal and proximal longitudinally) of the racket face, the longitudinal axis between the same two markers, and the medio-lateral axis perpendicular to this and between the midpoints of the two markers on each side of the racket face. Calculated impact locations in the longitudinal axis were offset proximally by the distance between shuttlecock tip and reflective tape centre $(11.4 \mathrm{~mm}$; Figure 1) to allow agreement between both measured (tip of shuttlecock) and calculated impact locations. Subsequent analyses in Stage 2 use non-corrected impact locations to represent contact with the shuttlecock centre of mass more accurately than would the tip of the shuttlecock. Impact locations (centre of the mark imparted by stencil ink; Figure 1) and racket marker tape were digitised (ImageJ, National Institutes of Health, University of Wisconsin, Wisconsin, US) three times per trial by the same investigator, with the tape providing a scale factor and two-dimensional local coordinate system equivalent to that in the curve fitting methodology above.

\section{Data Analysis}

$R^{2}$ and root mean square error (RMSE) values assessed the goodness of fit of the curves to the recorded shuttlecock coordinate data in each global axis. The absolute discrepancy between calculated and digitised (mean of three) impact locations were evaluated. Reliability of digitisation was assessed by Cronbach- $\alpha$ and interpreted as: excellent $\geq 0.9 ; 0.9>$ good $\geq 0.8 ; 0.8>$ acceptable $\geq 0.7 ; 0.7>$ questionable $\geq 0.6 ; 0.6>$ poor $\geq 0.5$; unacceptable $<0.5$ (Cronbach, 1951).

\section{Stage 2 - Effect of Impact Location on Shot Outcome \\ Data Collection}

Sixty-five (35 male; 30 female) international badminton players ( $23 \pm 5$ years, $1.75 \pm 0.08 \mathrm{~m}, 68.2 \pm 7.9 \mathrm{~kg}$ ) from 19 nations in 4 continents participated in this investigation, recorded on warm-up courts at the 2017 BWF World Championships ( $\mathrm{n}$ = 35; 14 male, 21 female) and at the National Badminton Centre, Milton Keynes, UK ( $\mathrm{n}=30 ; 21$ male, 9 female). Participants performed a series of forehand overhead smash trials $(37 \pm 6)$ at a position behind the centre on the opposite side of the court exactly as in Stage 1 to recreate match demands. Each shot followed a lifted feed from a shuttlecock launcher (BKL, Badenko, France) at a frequency of $0.25 \mathrm{~Hz}$ and at a trajectory agreed with an international badminton player and coach. Retro-reflective tape was attached to the shuttlecocks (AS50, Yonex, Japan) and each participant's own racket as described in Stage 1. Misshapen or broken shuttlecocks were removed.

\section{Data Reduction}

Racket-shuttlecock impact characteristics were calculated as described and validated in Stage 1. To minimise confounding influences of racket characteristics and speed, instantaneous post-impact shuttlecock speed as a percentage of the participant's maximum instantaneous post-impact shuttlecock speed was calculated for each trial. 
$\mathrm{R}^{2}$ and RMSE goodness of fit values were established and assessed as in Stage 1. Firstly, relationships between impact location and percentage of participant-specific maximal shuttlecock speed were assessed separately in each axis (medio-lateral and longitudinal) of the racket face's 2D local coordinate system. Secondly, a polynomial (quadratic) surface fit predicted percentage of maximal shuttlecock speed from impact location in both axes combined and defined an optimal impact location for generating post-impact shuttlecock speed. Instantaneous post-impact shuttlecock horizontal direction relative to a line normal to the racket face at impact was calculated from previously fit displacement-time curves, and compared to the medio-lateral impact location.

\section{Statistical Analysis}

All statistical analyses were performed within JASP (Amsterdam, Netherlands) version 0.9.2.0. Data were presented as mean \pm standard deviation, except for percentage of participant-specific maximum instantaneous post-impact shuttlecock speed and absolute differences in impact locations which were presented as median [interquartile range (IQR)] due to non-normality. A Bayesian statistical approach was used to provide probabilistic statements (Mengersen, Drovandi, Robert, Pyne, \& Gore, 2016; Sainani, 2018), with each analysis conducted using a JASP default 'noninformative' prior (Wang, Chow, \& Chen, 2005). Traditional frequentist statistics (i.e. $p$-values) were also reported for comparison. Pearson product moment and Kendall's tau-b ( $\mathrm{Tb}$ ) correlations were used to establish relationships in the case of normally and non-normally distributed dependent variables, respectively. Linear and polynomial regressions were used to provide predictive equations. The percentage of variance in the dependent variable explained by the independent variables was determined by Wherry's (1931) adjusted $R^{2}$. Bayes factor $\left(\mathrm{BF}_{10}\right)$ was reported to indicate the strength of the evidence for each analysis, interpreted as: $1 / 3<$ anecdotal $\leq 3 ; 3<$ moderate $\leq 10 ; 10<$ strong $\leq 30 ; 30<$ very strong $\leq 100$; extreme $>100$ (Lee \& Wagenmakers, 2013). Evidence for the alternative hypothesis was set as $\mathrm{BF}_{10}>3$ and for the null hypothesis $\mathrm{BF}_{10}<1 / 3$. Markov Chain Monte Carlo with Gibbs sampling (10000 samples) was used to make inferences, with 95\% credible intervals (Cl) (Ly, Verhagen, \& Wagenmakers, 2016; van Doorn et al., 2019).

\section{RESULTS}

\section{Stage 1 - Impact Location Methodology Validation}

$\mathrm{R}^{2}$ and RMSE of the pre- and post-impact shuttlecock curves averaged $0.98 \pm$ 0.04 and $3.0 \pm 1.3 \mathrm{~mm}$ respectively, while those for the racket curves averaged $1.00 \pm$ 0.00 and $1.9 \pm 0.9 \mathrm{~mm}$. Instantaneous post-impact shuttlecock speeds were $86.4 \pm 5.8$ $\mathrm{m} \cdot \mathrm{s}-1$ (range: 66.4 to $98.3 \mathrm{~m} \cdot \mathrm{s}^{-1} ; 89.4$ [IQR: 4.3 ]\% of participant-specific maximum speed). The digitisation process showed excellent reliability in both the medio-lateral $(\alpha=0.999)$ and longitudinal $(\alpha=1.000)$ axes of the racket face. Mean absolute differences between calculated (curve equations) and measured (digitisation) impact locations were 3.6 [IQR: 4.4$] \mathrm{mm}$ in the medio-lateral axis and 3.5 [IQR: 3.5$] \mathrm{mm}$ in the longitudinal axis.

\section{Stage 2 - Effect of Impact Location on Shot Outcome}

$\mathrm{R}^{2}$ and RMSE of the pre- and post-impact shuttlecock curves averaged $0.97 \pm$ 0.13 and $3.0 \pm 2.2 \mathrm{~mm}$ respectively, while those for the racket curves averaged $1.00 \pm$ 0.01 and $2.3 \pm 2.8 \mathrm{~mm}$. Instantaneous post-impact shuttlecock speeds were $82.1 \pm 9.5$ 
$\mathrm{m} \cdot \mathrm{s}^{-1}$ (range: 53.3 to $107.4 \mathrm{~m} \cdot \mathrm{s}^{-1} ; 92.3$ [IQR: 7.7$] \%$ of participant-specific maximum speed; Figure 2). Racket-shuttlecock impact locations averaged $1.27 \pm 1.86 \mathrm{~cm}$ medial and $0.60 \pm 2.71 \mathrm{~cm}$ longitudinally proximal of the racket head centre. Meaningful negative quadratic relationships with participant-specific percentage of maximal shuttlecock speed were observed for the impact location on the racket face, both medio-laterally $\left(\mathrm{Tb}=0.152 ; \mathrm{Cl}: 0.124,0.178 ; \mathrm{BF}_{10}=2.8 \times 10^{25}\right.$, extreme; $p<0.001$ ) and longitudinally $\left(\mathrm{Tb}=0.278 ; \mathrm{Cl}: 0.251,0.305 ; \mathrm{BF}_{10}=3.9 \times 10^{88}\right.$, extreme; $\left.p<0.001\right)$. Combining both medio-lateral and longitudinal impact locations within the polynomial (quadratic) surface fit explained $26.2 \%$ (Cl: $23.1 \%, 29.2 \%$ ) of observed variation in percentage of maximal shuttlecock speed (Eq. 3; $\mathrm{BF}_{10}=1.3 \times 10^{131}$, extreme; $p<$ 0.001). The optimal impact location for generating fast instantaneous post-impact shuttlecock speeds was $0.71 \mathrm{~cm}$ medial and $1.89 \mathrm{~cm}$ longitudinally distal of the racket face origin (midpoint of distal and proximal markers on the longitudinal axis).

$$
v=93.1+0.353 x+0.699 y-0.305 x^{2}+0.0429 x y-0.193 y^{2}
$$

where $v=$ percentage of participant-specific maximal shuttlecock speed; $x=$ mediolateral impact location (cm; medial is positive); and $y=$ longitudinal impact location (cm; distal is positive).
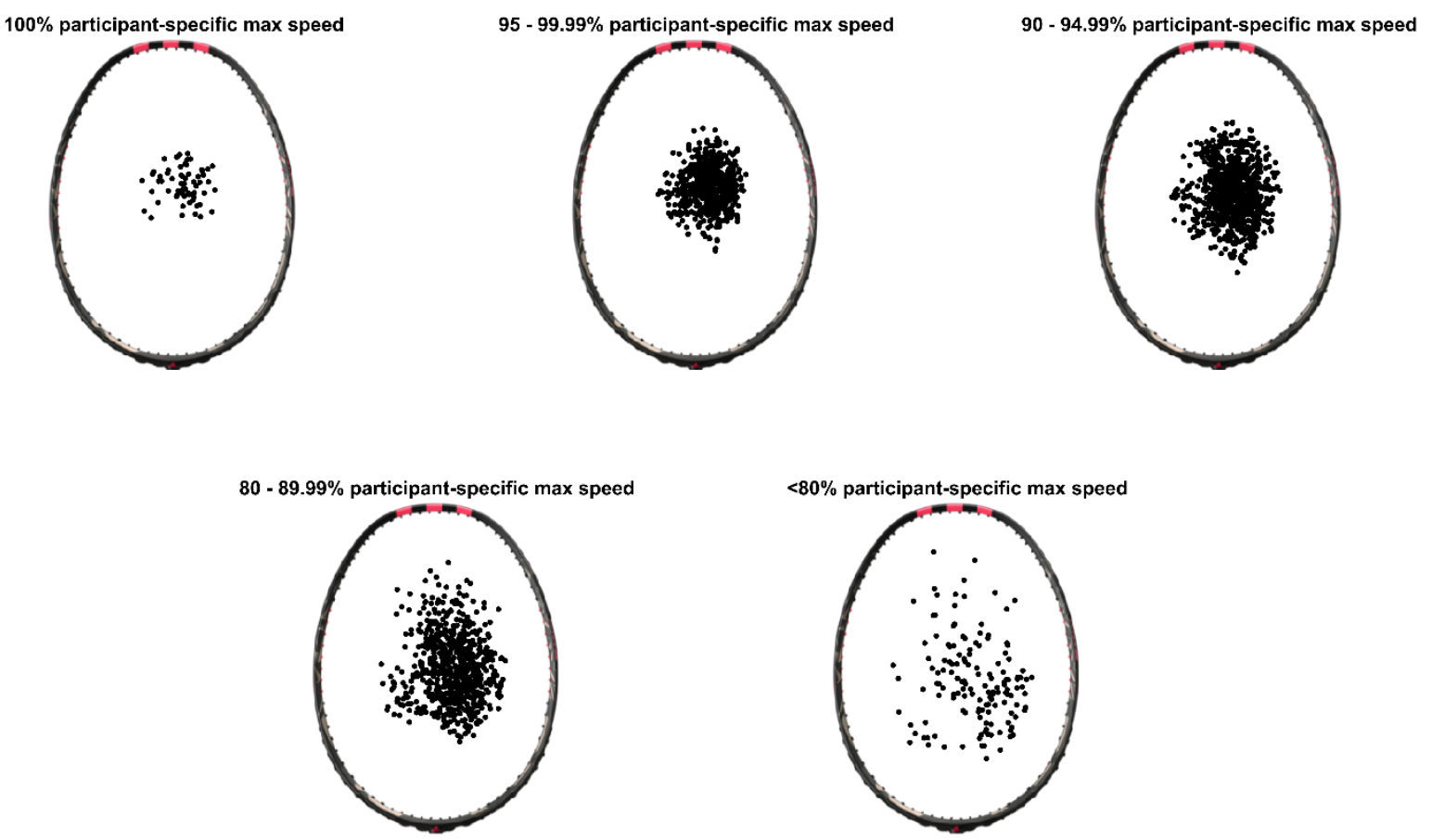

Figure 2 - Racket-shuttlecock impact locations categorised by percentage of participant-specific maximum instantaneous post-impact shuttlecock speed. Note: lateral towards left; medial towards right of racket face.

Medio-lateral impact location was related meaningfully to the difference between post-impact shuttlecock horizontal direction and a line normal to the racket face at impact (Eq. $4 ; r=0.635 ; \mathrm{Cl}: 0.610,0.658 ; \mathrm{BF}_{10}=\infty$, extreme; $p<0.001$; coefficient $\mathrm{Cl}$ : 1.08 to 1.19$)$. There was no relationship between longitudinal impact location and the measure of shuttlecock direction relative to the racket face $(r=-0.031 ; \mathrm{Cl}:-0.071$, $0.010 ; \mathrm{BF}_{10}=0.078$, strong evidence for $\mathrm{H}_{0} ; \mathrm{p}=0.136$ ). Impacts $0.56 \mathrm{~cm}$ medial of the racket face midline therefore resulted in the minimum post-impact shuttlecock 
deviations from a line normal to the racket face. Finally, the regression equations (Eq. 3 and 4) allowed visual representations of the effects of impact location on the outcome variables to be created (Figure 3).

$$
d=1.14 x-0.64
$$

where $d$ = deviation of immediate post-impact shuttlecock horizontal direction from a line normal to the racket face at impact ( ${ }^{\circ}$; medial is positive); and $x=$ mediolateral impact location on the racket face $(\mathrm{cm}$; medial is positive).
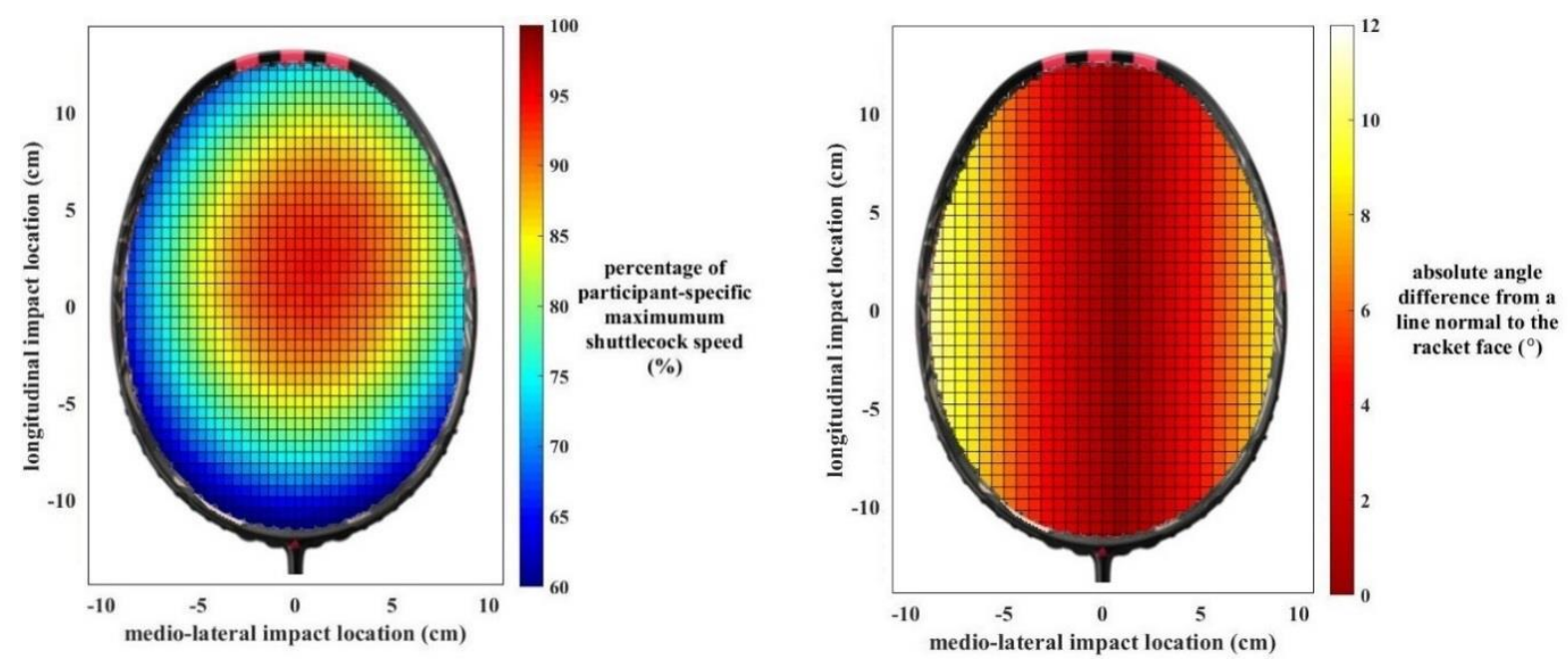

Figure 3 - Visual representations of the effect of impact location on instantaneous post-impact shuttlecock speed (left) and horizontal direction relative to optimal impact conditions (right).

\section{DISCUSSION}

Firstly, a methodology to determine badminton racket-shuttlecock impact location from three-dimensional motion capture data has been shown to be accurate within 3.6 [IQR: 4.4] mm medio-laterally and 3.5 [IQR: 3.5$] \mathrm{mm}$ longitudinally. Secondly, this method was utilised to determine the relationships between impact location and instantaneous post-impact shuttlecock speed and direction. The present study further reported the fastest badminton smash to date in the scientific literature $\left(107 \mathrm{~m} \cdot \mathrm{s}^{-1}\right)$.

The high $R^{2}$ and low RMSE for curve fitting justify use of the specified equations for shuttlecock and racket trajectories around impact. Measured errors in calculated racket-shuttlecock impact location indicate no major additional errors post-curve fitting, similar to in cricket batting (Peploe, McErlain-Naylor, Harland, Yeadon, et al., 2018). In addition to accurate impact locations, this method further provides instantaneous postimpact shuttlecock speed and direction, overcoming difficulties associated with average velocities during which the shuttlecock decelerates greatly after impact (Nakagawa et al., 2012). A more precise estimation of impact timing further enables more accurate estimates of joint or segment kinematics at this time (e.g. when correlating such parameters against instantaneous post-impact shuttlecock speed: King et al., 2020), particularly for fast moving distal aspects. This methodology and validation may have applications across other racket sports such as tennis and squash.

The presence of an optimal impact location for shuttlecock speed, whereby impact further from that spot generates lower shuttlecock speeds is in support of the present study's hypothesis. Although this agrees with previous findings in tennis (Elliott et al., 1980), the medially off-centre, and distal, location of this spot reflects the investigation of a representative sporting technique rather than a stationary racket. During the smash, 
longitudinally distal points on the racket face will exhibit greater linear velocities than more proximal points for any generated angular velocity of the racket about its transverse axis. Likewise, rapid radio-ulnar pronation around impact causes racket angular velocity about its longitudinal axis, resulting in more medial aspects of the racket experiencing greater linear velocities in the anterior direction than more lateral aspects (Tang, Abe, Katoh, \& Ae, 1995). Consequently, the majority of impacts generated by elite players are shifted medially on the racket face (Figure 2). Players and coaches should consider that the accuracy of racket-shuttlecock impact location accounts for around a quarter of variation in instantaneous post-impact shuttlecock speed amongst international players, regardless of the racket head speed generated by preceding whole-body kinematics. Indeed, whilst such factors make it possible for relatively slow smashes to be hit close to the optimal location, it would appear impossible to hit maximal speed smashes near to the racket frame due to a decreased coefficient of restitution (Brody, 1997) (Figure 2). Future research should investigate kinematic and/or perception-action related factors contributing to the within-participant variation in racketshuttlecock impact location observed (Figure 2).

The linear relationship between medio-lateral impact location and post-impact horizontal shuttlecock direction relative to the racket face again supports the present study's hypothesis. Impacts occurring medially or laterally towards the edges of the racket face caused the shuttlecock to depart on a trajectory towards the same side as the impact, as previously reported in other sports and likely due to increased racket polar rotation (Knudson, 1993; Peploe, McErlain-Naylor, Harland, \& King, 2018; Symes, 2006). Impact locations one, two, or three standard deviations (pooled standard deviation for all players) from the optimal location for direction would cause medio-lateral shuttlecock deviations of $0.25 \mathrm{~m}(\mathrm{Cl}: 0.23,0.26 \mathrm{~m}), 0.50 \mathrm{~m}(\mathrm{Cl}: 0.47,0.52 \mathrm{~m})$, or $0.75 \mathrm{~m}$ $(\mathrm{Cl}: 0.70,0.78 \mathrm{~m})$, respectively after traveling half a court length $(6.7 \mathrm{~m})$ anteriorly (Figure 4). Lateral impacts resulted in greater deviations than equivalently medial impacts, likely due to the greater linear racket velocity at medial aspects as previously discussed and hence shorter contact durations in which for racket polar rotation to occur (Haake, Carré, \& Goodwill, 2003).

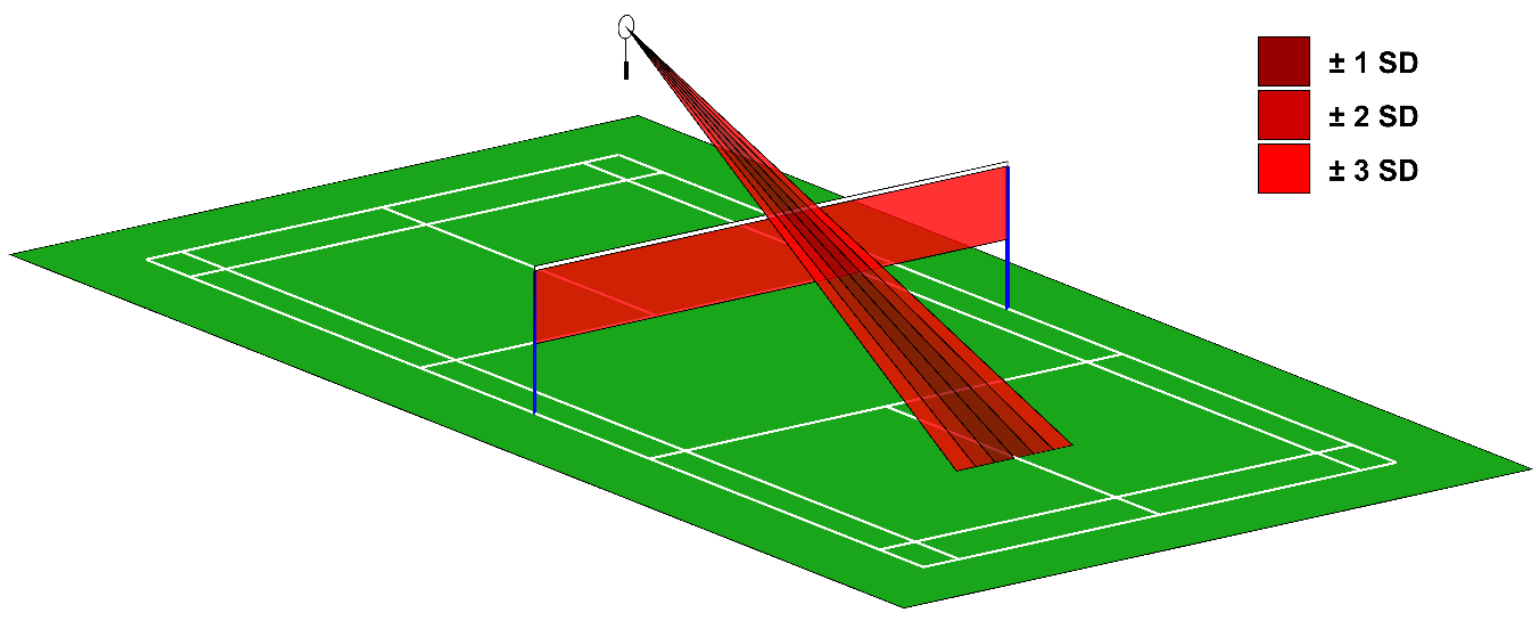

Figure 4 - Horizontal post-impact shuttlecock direction relative to a line normal to the racket face at impact as a result of medio-lateral racket-shuttlecock impact locations one, two, and three standard deviations from the optimal location.

It is necessary to consider the combined effects on speed and direction when describing the margin for error afforded to international badminton players during the 
smash. Medial impacts result in greater instantaneous post-impact shuttlecock speeds and lesser deviation in direction compared to equivalently lateral impacts (Figure 3). Maintaining consistency of racket-shuttlecock impact location within one, two, or three pooled standard deviations of the overall pooled mean impact location (Figure 5) would result in the reductions in instantaneous post-impact shuttlecock speeds of up to 5.3, 13.8 and $26.9 \%$, respectively, compared with those generated at the optimal impact location for speed. These same levels of consistency in impact location would result in horizontal post-impact shuttlecock direction deviations relative to a line normal to the racket face at impact of up to $2.9^{\circ}, 5.0^{\circ}$, and $7.2^{\circ}$ respectively. It is therefore practical for players/coaches to be aware of the importance and effect of impact location on shot outcome, where optimal impact locations occur slightly medial and longitudinally distal of the racket face geometric centre. Whilst this should be achieved with the greatest possible racket head speed, doing so at the expense of accurate and consistent racketshuttlecock impact locations may result in unwanted and perhaps unsuccessful shuttlecock trajectories.

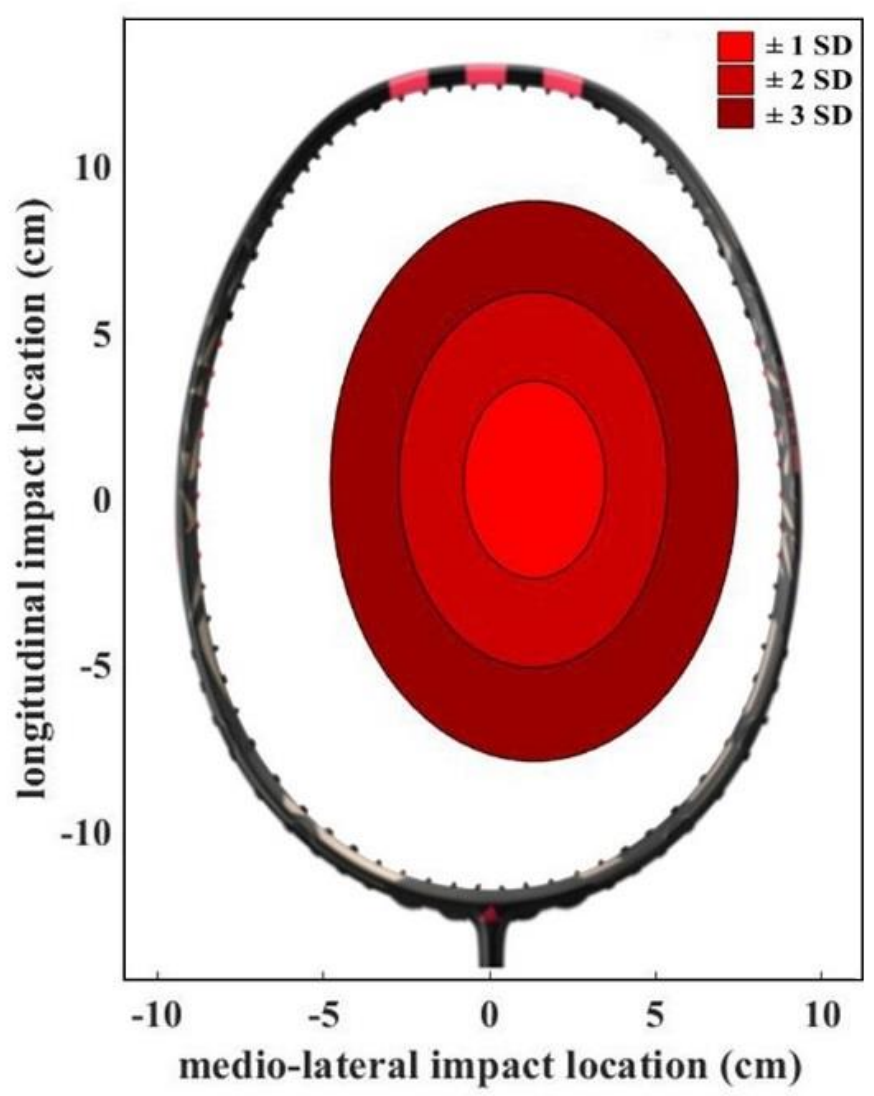

Figure 5 - Racket-shuttlecock impact locations within one, two, and three standard deviations of the mean. Note: lateral towards left; medial towards right of racket face.

It must also be considered that each participant used their own racket for purposes of familiarity and to avoid alteration in swing kinematics (Mitchell, Jones, \& King, 2000). Racket mass, stiffness, and string properties (as well as participant sex and technique) were therefore not controlled other than through the expression of instantaneous postimpact shuttlecock speeds relative to participant-specific maxima. However, the observed relationships were possibly damped by the influence of such characteristics and may be more extreme for any individual player and racket (Arianto, Nuri, \& Yulianto, 2017; Nasruddin et al., 2016; Vanasant, Mingkhumlert, \& Limroongreungrat, 2013). The same is true of within-participant variation in generated racket head speeds. It is not 
clear to what extent the 1 ms racket-shuttlecock contact durations of Cohen et al. (2015) are true for the elite players in the present study. Sensitivity analysis revealed that a $10 \%$ change in the contact duration parameter resulted in a calculated mean $0.2 \%$ change in instantaneous post-impact shuttlecock speed and $\leq 1 \mathrm{~mm}$ change in impact locations. The methodology used has been shown to calculate accurate impact locations, and such uniform changes would again be extremely unlikely to affect the relationships investigated in the present study. Similarly, validation using hand-fed standing forehand overhead smashes is unlikely to affect the validity of the methodology later applied to machine-fed jump smashes, especially given the similar instantaneous post-impact shuttlecock speeds $\left(86.4 \pm 5.8\right.$ vs $\left.82.1 \pm 9.5 \mathrm{~m} \cdot \mathrm{s}^{-1}\right)$.

\section{CONCLUSIONS}

In conclusion, this study has presented and validated a methodology for accurate determination of badminton racket-shuttlecock impact locations from three-dimensional motion capture data. Subsequent investigation has highlighted the margin for error in racket-shuttlecock impact location available to international players as impacts away from the optimal location on the racket cause a reduction in instantaneous post-impact shuttlecock speed and a deviation in shot direction. Radio-ulnar pronation during the badminton smash results in optimal impact locations on the racket face slightly medial of centre for both speed and direction. The greater linear velocities at more distal positions on the racket face result in an optimal impact location for instantaneous postimpact shuttlecock speed that is slightly distal of the racket face centre. It is therefore a practical recommendation to players and coaches that, in order to achieve the desired shot outcomes of high shuttlecock velocity and accuracy, techniques should be developed such that maximal racket head speed occurs without compromising on consistent impact locations.

\section{ACKNOWLEDGEMENTS}

This project was part-funded by the Badminton World Federation (BWF). The authors report no conflicts of interest, and wish to thank both the BWF and Badminton England for their help with participant recruitment.

\section{REFERENCES}

Arianto, I. S., Nuri, N., \& Yulianto, A. (2017). Effect of the pull and diameter string of badminton racket based on coeffisient of restitution Value. Journal Of Natural Sciences And Mathematics Research, 2(1), 85-90. https://doi.org/10.21580/jnsmr.2016.1.1.1639

Banwell, G. (2013). Impulsive sound quality of tennis rackets. Loughborough University.

Bower, R. (2012). The sweet spot of a cricket bat for low speed impacts. Sports Engineering, 15(2), 53-60. https://doi.org/10.1007/s12283-012-0087-6

Brody, H. (1995). How would a physicist design a tennis racket? Physics Today, 48(3), 26-31.

Brody, H. (1997). The physics of tennis. III. The ball-racket interaction. American Journal of Physics, 65(10), 981-987. https://doi.org/10.1119/1.18701

Brody, H., Cross, R., \& Lindsey, C. (2002). The physics and technology of tennis. California, USA: Racquet Tech Publishing.

Brody, Howard, \& Roetert, P. (2004). Optimizing ball and racket interaction. https://doi.org/10.1007/978-1-4419-8887-4 8 
Cohen, C., Texier, B. D., Quéré, D., \& Clanet, C. (2015). The physics of badminton. New Journal of Physics, 17(6), 063001. https://doi.org/10.1088/13672630/17/6/063001

Cronbach, L. J. (1951). Coefficient alpha and the internal structure of tests. Psychometrika, 16(3), 297-334. https://doi.org/10.1007/BF02310555

Elliott, B. C., Blanksby, B. A., \& Ellis, R. (1980). Vibration and rebound velocity characteristics of conventional and oversized tennis rackets. Research Quarterly for Exercise and Sport, 508-615. https://doi.org/10.1080/02701367.1980.10609321

Gawande, J. S., Kale, S. S., \& Pachpore, S. S. (2017). Failure investigation of badminton racket using modal analysis. International Journal for Scientific Research \& Development, 5(2), 1849-1856.

Guinness World Records. (2017). Fastest badminton hit in competition (male). Retrieved June 19, 2019, from https://www.guinnessworldrecords.com/worldrecords/fastest-badminton-hit-in-competition-(male)/

Haake, S. J., Carré, M. J., \& Goodwill, S. R. (2003). The dynamic impact characteristics of tennis balls with tennis rackets. Journal of Sports Sciences, 21(10), 839-850. https://doi.org/10.1080/0264041031000140329

King, M., Towler, H., Dillon, R., \& McErlain-Naylor, S. (2020). A correlational analysis of shuttlecock speed kinematic determinants in the badminton jump smash. Applied Sciences, 10(4), 1248. https://doi.org/10.3390/app10041248

Knudson, D. (1993). Effect of string tension and impact location on ball rebound accuracy in static tennis impacts. Journal of Applied Biomechanics, 9(2), 143-148. https://doi.org/10.1123/jab.9.2.143

Kotze, J., Mitchell, S. R., \& Rothberg, S. J. (2000). The role of the racket in high-speed tennis serves. Sports Engineering, 3(2), 67-84. https://doi.org/10.1046//.14602687.2000.00050.x

Kwan, M. (2010). Designing the world's best badminton racket (Aalborg University). Retrieved from http://www.worldbadminton.com/reference/documents/Kwan 2010 Designing Ra cket.pdf

Kwan, M., Andersen, M. S., Cheng, C., Tang, W., \& Rasmussen, J. (2011). Investigation of high-speed badminton racket kinematics by motion capture. Sports Engineering, 13(2), 57-63. https://doi.org/10.1007/s12283-010-0053-0

Kwan, M., \& Rasmussen, J. (2010). The importance of being elastic: Deflection of a badminton racket during a stroke. Journal of Sports Sciences, 28(5), 505-511. https://doi.org/10.1080/02640410903567785

Lee, M. D., \& Wagenmakers, E. J. (2013). Bayesian data analysis for cognitive science: A practical course. New York, NY: Cambridge University Press.

Ly, A., Verhagen, J., \& Wagenmakers, E.-J. (2016). Harold Jeffreys's default Bayes factor hypothesis tests: Explanation, extension, and application in psychology. Journal of Mathematical Psychology, 72, 19-32. https://doi.org/10.1016/j.jmp.2015.06.004

Mcintyre, D. R., \& Pfautsch, E. W. (1982). A kinematic analysis of the baseball batting swings involved in opposite-field and same-field hitting. Research Quarterly for Exercise and Sport, 206-213. https://doi.org/10.1080/02701367.1982.10609341 
Mengersen, K. L., Drovandi, C. C., Robert, C. P., Pyne, D. B., \& Gore, C. J. (2016). Bayesian estimation of small effects in exercise and sports science. PLOS ONE, 11(4), e0147311. https://doi.org/10.1371/journal.pone.0147311

Miller, S. (2006). Modern tennis rackets, balls, and surfaces. British Journal of Sports Medicine, 40(5), 401-405. https://doi.org/10.1136/bjsm.2005.023283

Mitchell, S. R., Jones, R., \& King, M. (2000). Head speed vs. racket inertia in the tennis serve. Sports Engineering, 3(2), 99-110. https://doi.org/10.1046//.14602687.2000.00051.x

Nakagawa, K., Hasegawa, H., Murakami, M., \& Obayashi, S. (2012). Aerodynamic properties and flow behavior for a badminton shuttlecock with spin at high reynolds numbers. Procedia Engineering, 34, 104-109. https://doi.org/10.1016/j.proeng.2012.04.019

Nasruddin, F. A., Harun, M. N., Syahrom, A., Abdul Kadir, M. R., Omar, A. H., \& Öchsner, A. (2016). Finite element analysis on badminton racket design parameters. https://doi.org/10.1007/978-3-319-21735-2

Noble, L., \& Eggeman, G. W. (1982). Baseball bat instrumentation for the measurement of hand forces. Journal of Biomechanics, 15(4), 341.

Peploe, C., McErlain-Naylor, S. A., Harland, A. R., \& King, M. A. (2018). The relationships between impact location and post-impact ball speed, bat torsion, and ball direction in cricket batting. Journal of Sports Sciences, 36(12), 1407-1414. https://doi.org/10.1080/02640414.2017.1389484

Peploe, C., McErlain-Naylor, S. A., Harland, A. R., \& King, M. A. (2019). Relationships between technique and bat speed, post-impact ball speed, and carry distance during a range hitting task in cricket. Human Movement Science, 63, 34-44. https://doi.org/10.1016/j.humov.2018.11.004

Peploe, C., McErlain-Naylor, S. A., Harland, A. R., Yeadon, M. R., \& King, M. A. (2018). A curve fitting methodology to determine impact location, timing, and instantaneous post-impact ball velocity in cricket batting. Proceedings of the Institution of Mechanical Engineers, Part P: Journal of Sports Engineering and Technology, 232(3), 185-196. https://doi.org/10.1177/1754337117723275

Sainani, K. L. (2018). The problem with "Magnitude-based Inference." Medicine \& Science in Sports \& Exercise, 50(10), 2166-2176. https://doi.org/10.1249/MSS.0000000000001645

Shibayama, H., \& Ebashi, H. (1983). Development of a motor skill using the golf swing from the viewpoint of the regulation of muscle activity. Biomechanics VIII, 1, 895902.

Stretch, R., Buys, F., Du Toit, E., \& Viljoen, G. (1998). Kinematics and kinetics of the drive off the front foot in cricket batting. Journal of Sports Sciences, 16(8), 711-720. https://doi.org/10.1080/026404198366344

Symes, A. W. (2006). The effect of mass distribution on cricket bat playing properties (Loughborough University). Retrieved from https://dspace.lboro.ac.uk/dspaceispui/handle/2134/11153

Tang, H. P., Abe, K., Katoh, K., \& Ae, M. (1995). Three dimensional cinematographic analysis of the badminton forehand smash: movements of the forearm and hand. In T. Reilly, M. Hughes, \& A. Lees (Eds.), Science and Racket Sports (pp. 113-120). $\mathrm{E} \& \mathrm{FN}$ SPON, London. 
Tong, Y.-M., \& Hong, Y. (2000). The playing pattern of world's top single badminton players. 18th International Symposium on Biomechanics in Sports. Hong Kong, China.

van Doorn, J., van den Bergh, D., Bohm, U., Dablander, F., Derks, K., Draws, T., ... Wagenmakers, E.-J. (2019). The JASP guidelines for conducting and reporting a Bayesian analysis. PsyArxiv Preprint. https://doi.org/10.31234/osf.io/yqxfr

Vanasant, T., Mingkhumlert, S., \& Limroongreungrat, W. (2013). The effect of string tension on shuttlecock velocity. 31 International Conference on Biomechanics in Sports. Retrieved from https://ojs.ub.uni-konstanz.de/cpa/article/view/5682

Wang, H., Chow, S.-C., \& Chen, M. (2005). A Bayesian approach on sample size calculation for comparing means. Journal of Biopharmaceutical Statistics, 15(5), 799-807. https://doi.org/10.1081/BIP-200067789

Wherry, R. J. (1931). A new formula for predicting the shrinkage of the coefficient of multiple correlation. The Annals of Mathematical Statistics, 2(4), 440-457.

Zhang, Z., Li, S., Wan, B., Visentin, P., Jiang, Q., Dyck, M., ... Shan, G. (2016). The influence of $X$-Factor (trunk rotation) and experience on the quality of the badminton forehand smash. Journal of Human Kinetics, 53, 9-22. https://doi.org/10.1515/hukin-2016-0006 